Vị trí xương di căn phát hiện bằng xa hình là 45, trên CT là 23.

Phát hiện di căn xương bằng chụp xạ hình có độ nhạy $100 \%$, độ đặc hiệu 79.5\%; CT độ nhạy $72.2 \%$, đô đặc hiệu $89.7 \%$.

Độ chính xác chẩn đoán của xạ hình xương $86.0 \%$ cao hơn của chụp CT 84.2\%.

\section{TÀI LIÊU THAM KHẢO}

1. Đào Đức Tiến. (2018). Đánh giá kết quả điều trị ung thư biểu mô tế bào gan bằng phương pháp tắc mach xạ trị với hạt vi cầu gắn YTTRIUM-90, Luận án tiến sĩ y học, Viện nghiên cứu khoa học Y dược lâm sàng 108.

2. Sakdapetsiri W. (2017). Agreement of bone metastasis detection between bone scintigraphy and whole body-MRI in hepatocellular carcinoma. Chula Med J, 61: 322-331.

3. Yen RF, Chen CY, Cheng MF, et al. (2010). The diagnostic and prognostic effectiveness of $\mathrm{F}$ 18 sodium fluoride PET-CT in detecting bone metastases for hepatocellular carcinoma patients. Nucl Med Commun., 31(7):637-45.
4. Langsteger $W$, Rezaee $A$, Pirich $C$, et al. (2016). 18F-NaF-PET/CT and 99mTc-MDP Bone Scintigraphy in the Detection of Bone Metastases in Prostate Cancer. Semin Nucl Med, 46(6):491-501.

5. Verma S, Kumar N, Kheruka S, et al. (2016) Extraosseous 99mTc-methylene diphosphonate uptake on bone scan: Unusual scenario. Indian J Nucl Med, 31(4): 280-282.

6. Zhang L, He Q, Zhou T, et al. (2019). Accurate characterization of 99mTc-MDP uptake in extraosseous neoplasm mimicking bone metastasis on whole-body bone scan: contribution of SPECT/CT. BMC Medical Imaging, 19: 44.

7. Chen CY, Wu K, Lin WH, et al. (2012). High false negative rate of Tc-99m MDP whole-body bone scintigraphy in detecting skeletal metastases for patients with hepatoma. Journal of the Formosan Medical Association, 111(3): 140-146.

8. Bolaños DC, Wong LR, González DN, et al. (2017). Sensitivity, Specificity, Predictive Values, and Accuracy of Three Diagnostic Tests to Predict Inferior Alveolar Nerve Blockade Failure in Symptomatic Irreversible Pulpitis. Pain Research and Management, 2017, https:// doi.org/10.1155/2017/3108940.

\title{
KIẾN THỨC, THÁI Độ TRONG PHÒNG CHỐNG VÀ CHĂM SÓC NGƯỜI NHIỄM HIV/AIDS CỦA SINH VIÊN ĐIỀU DƯỠNG TRƯỜ'NG ĐẠI HỌC Y HÀ NỘI VÀ THÀNH TÂY NĂM 2017
}

Phạm Thị Thùy Dung*, Nguyễn Thị Hồng Anh*, Nguyễn Hồng Trang*

\section{TÓM TẮT}

Đặt vấn đề: Đánh giá kiến thức, thái độ về việc chăm sóc cho người nhiễm HIV/AIDS của sinh viển ngành Điều dưỡng - những người sẽ thường xuyên tiếp xúc, chăm sóc trực tiếp với các bênh nhân - là rất quan trọng. Tuy nhiển, tại Việt Nam có rất ít nghiên cứu thức hiên trên đối tượng này. Muc tiêu: Mô tả kiến thức, thái độ về phòng chống và chăm sóc người bênh HIV/AIDS của sinh viên năm thứ 3 và thứ 4 tai trường đại học $Y$ Hà Nội và đại học Thành Tây năm 2017; Xác định một số yếu tố liền quan giữa kiến thức với thái độ về phòng chống và chăm sóc người bệnh HIV/AIDS của đối tượng nghiên cứu. Phương pháp: Nghiên cứu mô tả cắt ngang có phân tích. Kết quả: Kiến thức, phòng chống và chăm sóc người bệnh HIV/AIDS của sinh viên điều dưỡng năm thứ 3 và thứ 4 tại hai trường chưa cao $(63 \%)$, trong đó tỷ lệ đạt ở sinh viên $Đ H$ Y Hà Nội là $80,1 \%$, và sinh viên trường ĐH Thành Tây là 41,2\%. Điểm trung bình chung về kiến thức HIV/AIDS đat của sinh viên của 2 trường là $20 \pm 3,2$, trong đó trường ĐH Y Hà Nội $(21,6 \pm 2,5)$ cao hơn điểm trung bình của sinh viên ĐH Thành Tây

* Dai hoc Phenikaa, Hà Nôi

Chịu trách nhiệm chính: Phạm Thị Thùy Dung Email: phamdung0610@gmail.com

Ngày nhân bài: 21.12.2020

Ngày phản biên khoa hoc: 27.01.2021

Ngày duyệt bài: 4.2.2021
$(18,4 \pm 3,8)$. Về thái độ: có tới $15,5 \%$ sinh viên có xa lánh, đồ lôi cho người có HIV; $9,1 \%$ sinh viên đồng ý/rất đồng ý rằng "người nghiện chích ma túy đáng bị mắc HIV"; và sinh viên có thái độ "đồng cảm" với "trẻ em/người nhiểm HIV do truyền máu hơn là người nhiễm HIV do tiêm chích ma túy" chiếm 34,3\%. Kết luân: Các trường đào tạo điều dưỡng cần trang bị thểm cho các em sinh viển kiến thức về dự phòng và chăm sóc người nhiễm HIV/AIDS, kiểm soát nhiễm khuẩn trong HIV/AIDS, từ đó giảm thái độ kỳ thị với người nhiễm HIV/AIDS.

\section{SUMMARY \\ KNOWLEDGE AND ATTITUDES IN THE \\ PREVENTION AND CARE FOR PATIENTS WITH HIV/AIDS AMONG NURSING STUDENTS OF HA NOI MEDICAL UNIVERSITY AND THANH TAY UNIVERSITY IN 2017 \\ Background: Nursing students are expected to} have certain knowledge and attitudes about caring for people with HIV/AIDS because they will play an important role in care for those patients in later career. However, in Vietnam, limit is known about their knowledge and attitudes about this issue. Objectives: (1) Describe knowledge and attitudes about and care for patient with HIV/AIDS among students of $3^{\text {rd }}$ and $4^{\text {th }}$ year at Hanoi Medical University and Thanh Tay University in 2017; (1) Identify some factors related to subjects knowledge of 
care for patients with HIV/AIDS and their attitudes. Methodology: A cross-sectional descriptive study was used. Results: Knowledge of prevention and care of HIV / AIDS patients among nursing students in the 3rd and 4th years at the two universities was not high $(63 \%)$, of which the rate of students at Hanoi Medical University was $80.1 \%$, and Thanh Tay University was $41.2 \%$. The average score on HIV / AIDS knowledge of students of the two universities

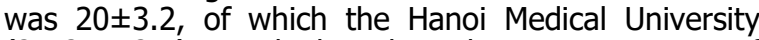
$(21.6 \pm 2.5)$ was higher than the average score of students of Thanh Tay University (18.4 \pm 3.8$)$. Regarding the student's attitudes: up to $15.5 \%$ of students were shunned and blamed people with HIV/AIDS; $9.1 \%$ of students agreed / strongly agreed that "drug users deserve infecting HIV"; and students had a "sympathetic" attitude towards "children / people infected with HIV due to blood transfusion than people infected with HIV due to drugs injection", accounted for $34.3 \%$. Conclusion: Nursing educated schools need to equip students with knowledge about prevention and care of people with HIV/AIDS, infection control related to HIV/AIDS, thereby reducing stigma towards people with HIV/AIDS.

\section{I. ĐĂT VẤN ĐỀ}

Theo ước tính của Tổ chức $Y$ tễ thế giới tính đến $1 / 2016$, trên toàn thế giới số người có HIV/AIDS vẫn còn sống là 35 triệu người, số người nhiễm mới tại 119 quốc gia là 95 triệu người. Như vâyy, sự gia tăng nhanh chóng số người nhiễm HIV/AIDS đã trở thành một thảm họa đáng lo ngại trên toàn cầu.

Tại Việt Nam, tính đến ngày 31/12/2014, số lũy tích được báo cáo là 226.964 trường hợp nhiễm HIV, 71.433 trường hợp đã chuyển thành bệnh nhân AIDS và 71368 ca tử vong do HIV/AIDS [5]. Số người nhiễm HIV chủ yếu trong độ tuổi từ 30-39 chiếm 44\%. Số người nhiễm HIV hiện còn sống vẫn chủ yếu tập trung tại các tỉnh thành phố trọng điểm như Thành phố Hồ Chí Minh, Hà Nội, Hải Phòng [6].

Sự kỳ thị đối với những người mắc HIV/AIDS tại cộng đồng cũng như tại các cơ sở y tế luôn là mối quan tâm hàng đầu trong công tác phòng chống HIV/AIDS [1][2]. Sự kỳ thị từ phía nhân viên y tế vô hình trung đã có tác động nhất định đến sinh viên các ngành $y$, điều dưỡng thực hành tại bệnh viện [7]. Từ đó có thể ảnh hưởng xấu đến thái độ của các em khi hành nghề trong tương lai. Tuy nhiên, hiên chưa có nhiều nghiên cứu tìm hiểu kiến thức và thái độ của các sinh viên ngành điều dưỡng về chăm sóc người nhiễm HIV/AIDS. Do đó, chúng tôi thực hiện nghiên cứu "Kiến thức, thái độ trong phòng chống và chăm sóc người nhiễm HIV/AIDS của sinh viên điều dưỡng trường Đại học Y Hà Nội và Thành Tây năm 2017".

\section{II. ĐỐI TƯợNG VÀ PHƯƠNG PHÁP NGHIÊN CỨU}

Đối tượng nghiên cứu là các sinh viên ngành điều dưỡng tại 2 trường Đại học Y Hà Nội và Đại học Thành Tầy.

Tiêu chuẩn lựa chọn: Sinh viên năm thứ 3 và năm thứ 4 là đối tượng đã đi thực hành lâm sàng tại cơ sở y tế, có tiếp xúc với bệnh nhân HIV/AIDS; tự nguyên tham gia vào nghiên cứu.

Tiêu chuấn loại trừ: những sinh viên chưa đi thực hành lâm sàng, không muốn tham gia vào nghiên cứu. Chọn mẫu theo phương pháp chọn mẫu toàn bộ.

Phương pháp nghiên cứu được sử dụng là nghiên cứu mô tả cắt ngang có phân tích. Bộ công cụ được sử dụng đánh giá được xây dựng bởi Froman và cộng sự (1992) và Jordan (1991) đã được chuẩn hóa. Phương án trả lời sử dụng thang Likert gồm 5 và 6 mức độ từ hàn toàn đồng ý đến hoàn toàn đồng ý, mỗi câu trả lời sẽ có điểm số từ 1 (tương ứng với "hoàn toàn không đồng ý") cho đến 6 (tương ứng với "hoàn toàn đồng ý$^{\prime \prime}$ ).

\section{KẾT QUẢ NGHIÊN CỨU}

3.1 Thông tin chung về đối tượng nghiên cứu. Tỷ lệ sinh viên nữ của 2 trường $Đ H$ Thành Tây và $Đ H$ Y Hà Nội đều cao hơn tỷ lệ sinh viên nam. Đặc biệt ở Đ̇H Y Hà Nội tỷ lệ nứ chiếm $(93,4 \%)$ cao gấp 14 lần nam $(6,6 \%)$. Bảng trên cũng cho thấy sinh viên Trường $Đ H ~ Y$ Hà Nội có độ tuổi trung bình $(21,67)$ thấp hơn sinh viên trường ĐH Thành Tây $(22,6)$.

3.1.2 Thông tin về sinh viên từng chăm sóc người bệnh có HIV/AIDS

Bảng 2. Tỷ lệ SV đã từng chăm sóc người nhiếm HIV/AIDS theo trường học

\begin{tabular}{|c|c|c|c|c|c|c|}
\hline \multirow{2}{*}{$\begin{array}{c}\text { Số người nhiêm } \\
\text { HIV / AIDS } \\
\text { đã từnq chăm sóc }\end{array}$} & \multicolumn{2}{|c|}{$\begin{array}{l}\text { ĐH Y Hà Nội } \\
(n=166)\end{array}$} & \multicolumn{2}{|c|}{$\begin{array}{c}\text { ĐH Thành Tây } \\
(n=131)\end{array}$} & \multicolumn{2}{|c|}{$\begin{array}{c}\text { Chung } \\
(n=297)\end{array}$} \\
\hline & Số lượng & $\%$ & Số lượng & $\%$ & Số lượng & $\%$ \\
\hline Chưa bao giờ & 38 & 22,9 & 13 & 9,9 & 51 & 17,2 \\
\hline 1- 2 người & 49 & 29,5 & 50 & 38,1 & 99 & 33,3 \\
\hline 3-4 người & 14 & 8,4 & 33 & 25,1 & 47 & 15,8 \\
\hline Từ 5 người trở lên & 65 & 39,2 & 35 & 26,8 & 100 & 33,7 \\
\hline Tống & 166 & 100 & 131 & 100 & 297 & 100 \\
\hline
\end{tabular}

Tỷ lệ sinh viên chưa từng chăm sóc cho người nhiếm HIV/AIDS của trường ĐH Y Hà Nội $(22,9 \%)$ 
cao hơn so với trường ĐH Thành Tây $(9,9 \%)$.

3.2 Kiến thức, thái độ về HIV/AIDS của sinh viên 2 trường Đại học Y Hà Nội và Đại học Thành Tây

3.2.1 Kiến thức của sinh viên phòng và chăm sóc người nhiễm HIV/AIDS

Bảng 3.Kiến thức về phòng và chăm sóc người nhiểm HIV/AIDS của sinh viên 2 trường

\begin{tabular}{|c|c|c|c|c|c|c|}
\hline \multirow{2}{*}{ Kiến thức } & \multicolumn{2}{|c|}{ ĐH Y Hà Nội $(\mathbf{n = 1 6 6 )}$} & \multicolumn{2}{c|}{ ĐH Thành Tây $(\mathbf{n = 1 3 1})$} & \multicolumn{2}{c|}{ Chung $(\mathbf{n = 2 9 7})$} \\
\cline { 2 - 7 } & Số lượng & $\mathbf{\%}$ & Số lượng & $\mathbf{\%}$ & Số lượng & $\%$ \\
\hline Kiến thức đạt & 133 & 80,1 & 54 & 41,2 & 187 & 63 \\
\hline Kiến thức không đạt & 33 & 19,9 & 77 & 58,8 & 110 & 37 \\
\hline
\end{tabular}

Nhân xét: tỳ lệ sinh viên có kiến thức về HIV/AIDS đat chiếm tỷ lê không cao (63\%), trong đó tỳ

lệ đạt về kiến thức của sinh viên trường ĐH Thành Tây chỉ là $41,2 \%$ và số sinh viên không đạt chiếm tỷ lệ $37 \%$.

3.2.2 Thái độ với người nhiễm HIV/AIDS và chăm sóc người nhiễm HIV/AIDS

Bảng 4. Thái độ đôi với người nhiếm HIV/AIDS và thái độ trong chăm sóc cho người nhiếm HIV/AIDS phân theo trường học

\begin{tabular}{|c|c|c|c|}
\hline \multirow{2}{*}{ Điểm thái độ } & $\begin{array}{c}\text { DH Y Hà Nội } \\
\text { (n=166) }\end{array}$ & $\begin{array}{c}\text { ĐH Thành Tây } \\
\text { (n=131) }\end{array}$ & $\begin{array}{c}\text { Chung } \\
\text { (n=297) }\end{array}$ \\
\cline { 2 - 4 } & TB \pm SD & TB \pm SD & TB \pm SD \\
\hline Điểm thái độ đối với người nhiếm HIV/AIDS & $62,6 \pm 5,0$ & $62,4 \pm 6,0$ & $62,5 \pm 5,5$ \\
\hline Điếm thái độ trong việc chăm sóc người nhiếm HIV/AIDS & $37,7 \pm 3,7$ & $39,5 \pm 3,8$ & $38,6 \pm 3,75$ \\
\hline \multicolumn{3}{|c|}{$p<0,01$} \\
\hline
\end{tabular}

Tổng điểm tối đa thái độ với người nhiễm và thái độ trong chăm sóc $=105$

Điểm về thái độ với người nhiê̂m HIV chung về thái độ với người nhiễm của 2 trường là 101, trong đó điểm trung bình của 2 trường là ngang nhau.

Bảng 5. Điểm thái độ "xa lánh" đối với người nhiễm HIV/AIDS của sinh viên

\begin{tabular}{|c|c|c|c|}
\hline Câu hỏi & $\begin{array}{c}\text { ĐH Y Hà Nội } \\
(n=166) \\
\text { TB } \pm \text { SD }\end{array}$ & \begin{tabular}{|c|} 
ĐH Thành \\
Tây $(n=131)$ \\
TB \pm SD
\end{tabular} & $\begin{array}{c}\text { Chung } \\
(n=297) \\
\text { TB } \pm \text { SD }\end{array}$ \\
\hline Những người nhiêm HIV/AIDS phải tự trách bản thân & $2,22 \pm 0,07$ & $2,31 \pm 0,92$ & $2,26 \pm 0,99$ \\
\hline Những người nhiếm HIV/AIDS đáng phải bị như vậy & $1,94 \pm 0,07$ & $2,03 \pm 0,85$ & $1,98 \pm 0,95$ \\
\hline $\begin{array}{c}\text { Không nên đế bệnh nhân có HIV chung phòng với } \\
\text { những bệnh nhân khác }\end{array}$ & $\begin{array}{c}2,96 \\
\pm 0,09\end{array}$ & $\begin{array}{c}3,01 \\
\pm 0,11 \\
\end{array}$ & $\begin{array}{c}2,98 \\
\pm 1,19 \\
\end{array}$ \\
\hline $\begin{array}{l}\text { Lo lắng đã đăt gia đình và bạn bè với nguy cơ mắc } \\
\text { HIV nếu đã tiếp xúc với một người nhiếm HIV/AIDS }\end{array}$ & $\begin{array}{c}2,43 \\
\pm 0,07\end{array}$ & $\begin{array}{c}2,44 \\
\pm 0,08\end{array}$ & $\begin{array}{c}2,44 \\
\pm 0,88\end{array}$ \\
\hline Trẻ em nên được chuyến đi nếu cha/mẹ bị nhiếm HIV & $2,22 \pm 0,07$ & $2,22 \pm 0,08$ & $2,22 \pm 0,90$ \\
\hline Những người nghiện chích ma tuý đáng bị mắc HIV & $2,27 \pm 0,07$ & $2,44 \pm 0,08$ & $2,35 \pm 0,87$ \\
\hline $\begin{array}{l}\text { Người phụ nữ biết mình có HIV (+) mà vần sinh con } \\
\text { phải bị lên án }\end{array}$ & $\begin{array}{c}2,35 \\
\pm 0,07\end{array}$ & $\begin{array}{c}2,44 \\
\pm 0,07\end{array}$ & $\begin{array}{c}2,39 \\
\pm 0,84 \\
\end{array}$ \\
\hline Tình dục đồng giới nên bị coi là bất hợp pháp & $2,40 \pm 0,09$ & $2,26 \pm 0,09$ & $2,34 \pm 1,06$ \\
\hline $\begin{array}{l}\text { Đồng cảm với người nhiểm HIV/AIDS do truyền máu } \\
\text { hơn là do tiêm chích ma túy }\end{array}$ & $\begin{array}{c}3,48 \\
\pm 0,08\end{array}$ & $3,46 \pm 0,09$ & $\begin{array}{c}3,47 \\
\pm 1,00\end{array}$ \\
\hline $\begin{array}{l}\text { Nếu phát hiện một người bạn có quan hệ đồng giới thì } \\
\text { sẽ không duy trì tình bạn nửa }\end{array}$ & $\begin{array}{c}2,11 \\
\pm 0,06\end{array}$ & $\begin{array}{c}2,00 \\
\pm 0,06\end{array}$ & $\begin{array}{r}2,06 \\
\pm 0,78\end{array}$ \\
\hline $\begin{array}{c}\text { Cảm thấy lo lắng về việc nhiếm HIV từ các mối quan } \\
\text { hệ xã hội }\end{array}$ & $\begin{array}{c}2,22 \\
\pm 0,06\end{array}$ & $\begin{array}{c}2,31 \\
\pm 0,07\end{array}$ & $\begin{array}{r}2,26 \\
\pm 0,78\end{array}$ \\
\hline $\begin{array}{l}\text { Trẻ em hoăc người mắc HIV do truyên máu thì đáng } \\
\text { được chăm sóc hơn do tiêm chích ma tuý }\end{array}$ & $\begin{array}{c}2,90 \\
\pm 0,08\end{array}$ & $\begin{array}{r}2,86 \\
\pm 0,09\end{array}$ & $\begin{array}{r}2,88 \\
\pm 1,06\end{array}$ \\
\hline $\begin{array}{l}\text { Lo lắng cho con cái có thế nhiêm HIV/AIDS nếu một } \\
\text { trong các giáo viên của chúng bị nhiếm HIV/AIDS }\end{array}$ & $\begin{array}{c}2,84 \\
\pm 0,07\end{array}$ & $\begin{array}{c}2,92 \\
\pm 0,08\end{array}$ & $\begin{aligned} & 2,88 \\
& \pm 0,94\end{aligned}$ \\
\hline $\begin{array}{l}\text { İt thông cảm với người bị nhiềm HIV/AIDS do quan hệ } \\
\text { tình dục bừa bãi }\end{array}$ & $\begin{array}{c}2,98 \\
\pm 0,08\end{array}$ & $\begin{array}{c}3,21 \\
\pm 0,09\end{array}$ & $\begin{array}{c}3,08 \\
\pm 1,06\end{array}$ \\
\hline Điềm TB & $2,5 \pm 0,07$ & $2,56 \pm 0,20$ & $2,39 \pm 0,95$ \\
\hline
\end{tabular}


*Ghi chú: Tổng điểm $=5$, điểm càng cao, thái độ càng xa lánh (điểm trung lập = 3)

Nhân xét: nhìn chung các câu hỏi liên quan đến thái độ "xa lánh" đối với người nhiễm HIV/AIDS đều có điểm trung bình từ xấp xỉ 2 , thái độ đồng cảm "trung lập", đồng cảm chưa cao. Sự khác biệt giữa sinh viên 2 trường về kiến thức này chưa ý nghĩa thống kê ( $p>0,05)$.

Bảng 7. Môi liên quan giữ̛a kiến thức học tập và thái độ với người nhiễm HIV/AIDS

\begin{tabular}{|c|c|c|c|}
\hline Kiến thức & $\begin{array}{c}\text { Thái độ } \\
\text { đống } \\
\text { cảm }\end{array}$ & $\begin{array}{c}\text { Thái độ } \\
\text { khống } \\
\text { đồng cảm }\end{array}$ & $\begin{array}{c}\text { OR, CI } \\
\mathbf{9 5 \%} \\
\mathbf{p}\end{array}$ \\
\hline $\begin{array}{c}\text { Kiến thức } \\
\text { đạt }\end{array}$ & 137 & 50 & $\begin{array}{c}\text { OR=1,18 } \\
\text { CI 95\% }\end{array}$ \\
\cline { 1 - 3 } $\begin{array}{c}0,69-1,98) \\
\text { Kiến thức } \\
\text { không đạt }\end{array}$ & 77 & 33 & 0,64 \\
\hline
\end{tabular}

Có mối liên quan giữa kiến thức học tập với thái độ với người nhiềm HIV, sinh viên có kiến thức đạt thì đồng cảm với người nhiễm cao hơn 1,18 lần so với những sinh viên không đạt về kiến thức HIV/AIDS với CI 95\% $(0,69-1,98)$.

\section{BÀN LUẬN}

Kết quả trả lời của sinh viên điều dưỡng cho thây kiến thức đạt chung về HIV/AIDS chưa cao $63 \%$, số sinh viên có kiến thức không đạt chiếm tới hơn $1 / 3(37 \%)$. Chỉ có $15,5 \%$ sinh viên có thái độ xa lánh, đổ lỗi cho người có HIV, rằng HIV/AIDS là sự trừng phạt cho hành vi xấu. Kết quả này thấp hơn nhiều so với nghiên cứu trên SV Y khoa tại Trung Quốc năm 1993 (tỷ lệ SV cho rằng HIV/AIDS là sự trừng phạt cho những người có hành vi xấu là 67,5\%)[3]. Sự khác nhau này có thể giải thích là do thời gian nghiên cứu khác nhau, ngoài ra yếu tố quan trọng góp phần làm tăng thái độ "đồng cảm" trong những năm gần đây những thông tin về HIV/AIDS được tuyên truyền, phổ biến rộng rãi hơn. Nghiên cứu tại Nhật năm 2000 trên 383 SV điều dươnng thì có 187 người (49\%) cho rằng không nên sống chung nhà với người nhiễm HIV/AIDS [4].

Liên quan tới thái độ với người nghiện chích ma túy bị nhiễm HIV, có $9,1 \%$ sinh viển đồng ý/rất đồng ý rằng "người nghiện chích ma túy đáng bị mắc HIV", từ $6,7 \%-27,6 \%$ có thái độ "đồng cảm" với "trẻ em/người nhiễm HIV do truyền máu hơn là người nhiễm HIV do tiêm chích ma túy". Nhìn chung, tỷ lệ sinh viên có thái độ "đồng cảm" đối với người nhiễm HIV/AIDS ở cả hai trường là cao. Điều này cũng tương đồng với nghiên cứu của Bruce và cộng sự (2005) [8].

\section{KẾT LUÂNN}

Kiến thức, phòng chống và chăm sóc người bệnh HIV/AIDS của sinh viên điều dưỡng năm thứ 3 và thứ 4 tại trường đại học $Y$ Hà Nội và đại học Thành Tây chưa cao $(63 \%)$, trong đó tỷ lệ đạt ở sinh viên $Đ H$ Y Hà Nội là $80,1 \%$ và của sinh viên trường ĐH Thành Tây là 41,2\%. Điểm trung bình chung về kiến thức HIV/AIDS đạt của sinh viên của 2 trường là $20 \pm 3,2$, trong đó trường $\mathrm{DH} Y$ Hà Nội $(21,6 \pm 2,5)$ cao hơn điểm trung bình của sinh viên ĐH Thành Tây $(18,4 \pm 3,8)$.

Về thái độ của sinh viên trong phòng và chăm sóc người nhiếm HIV/AIDS vẫn còn là vấn đề đáng quan ngaii. Có tới 15,5\% sinh viên có thái độ xa lánh, đổ lỗi cho người có HIV, 9,1\% sinh viên đồng ý/rất đồng ý rằng "người nghiện chích ma túy đáng bị mắc HIV"; và sinh viên có thái độ "đồng cảm" với "trẻ em/người nhiễm HIV do truyền máu hơn là người nhiễm HIV do tiêm chích ma túy"chỉ chiếm 34,3\%.

\section{KHUYẾN NGH!}

Các trường đào tạo điều dưỡng cần nhấn mạnh giảng dạy về cho sinh viên về kiến thức chung về HIV, cách phòng chống, chăm sóc và dự phòng trong chăm sóc người nhiễm HIV/AIDS và có buổi hệ thống lại kiến thức về HIV/AIDS trước khi sinh viên đi lâm sàng. Ngoài ra, sinh viên cần nắm rõ kiến thức về khử khuẩn- tiệt khuẩn dụng cụ chăm sóc, và các nhiễm trùng cơ hội thường gặp. Nâng cao công tác tuyên truyền giảm kỳ thị và sẵn sàng tích cực chăm sóc cho người nhiễm đối với sinh viên và nhân viên y tế, cũng như chú ý duy trì sự đồng cảm của những người chăm sóc, tiếp xúc với người nhiễm nhiều lần vì sự đồng cảm có xu hướng giảm theo kinh nghiệm chăm sóc.

\section{TÀI LIÊU THAM KHẢO}

1. Thi, M. D., Brickley, D. B., Vinh, D. T. et al., (2008), "A qualitative study of stigma and discrimination against people living with HIV in Ho Chi Minh City, Vietnam", AIDS Behav, 12(4 Suppl), pp. S63-70.

2. Sandelowski, M., Lambe, C. \& Barroso, J. (2004), "Stigma in HIV positive women", Journal of Nursing Scholarship, 36(2), pp. $122-128$.

3. Li, V.C., Cole, B. L., Zhang, S.Z. \& Chen, C.Z. (1993), "HIV-related knowledge and attitudes among medical students in China", AIDS Care, 5(3), pp. $305-312$.

4. Maswanya, E., Moji, K., Aoyagi, K. et al., (2000), "Knowledge and attitudes toward AIDS among female college students in Nagasaki, Japan", Health Education Research, 15(1), pp. 5 - 11

5. Bô̂ Y tế (2008), Báo cáo quốc gia lần thứ ba về việc thực hiện tuyên bố cam kết về HIV/AIDS. Hội thảo Đổng thuận Quốc gia, Hà Nội.

6. Vũ Thuý Hạnh (2003), Khảo sát một số bệnh nhiễm trùng cơ hội và mối liên quan với sư suy giảm miễn dịch ở người nhiếm HIV/AIDS điều trị 
tại Viện Y học Lâm sàng các bệnh Nhiệt đới. Luận vằn tốt nghiệp bác sỹ chuyên khoa II, Trường đại học Y Hà Nội

7. Bruce, K. E. \& Walker, L. J. (2001), "College students' attitudes about AIDS 1986 to 2000",
AIDS Education and Prevention, 13(5), pp. 428 - 437.

8. Duffy, L. (2005), "Suffering, shame, and silence: The stigma of HIV/AIDS", Journal of the Association of Nurses in AIDS Care, 16(1), pp. 13-20.

\section{HộI CHỨNG CHUYỂN HÓA Ở BÊNH NHÂN TĂNG SẢN THƯợ'NG THÂ̂N BẨM SINH THIỂU 21- $\alpha$ HYDROXYLASE}

\section{TÓM TẮT}

Hội chứng chuyển hóa $(\mathrm{HCCH})$ là một nhóm các yếu tố nguy cơ gây biến cố tim mạch và tăng tỷ lệ tử vong ở người trưởng thành cũng như trẻ em. Nhiều bằng chứng cho thấy bệnh nhân tăng sản thượng thận bẩm sinh thiếu 21-a hydroxylase (TSTTBS thiếu $21-\mathrm{OH}$ ) có nhiều yếu tố dẫn đến mắc hội chứng chuyển hóa và tăng nguy cơ mắc biến cố tịm mach. Mục tiêu: Xác định tỷ lệ mắc hội chứng chuyển hóa và mô tả đăc điểm của hội chứng chuyên hóa ở bênh nhân TSTTBS thiếu 21-OH. Đối tượng nghiên cứu: 52 bênh nhân TSTTBS thiếu $21-\mathrm{OH}$ từ 10 tuổi trở lên được chẩn đoán và điều trị tại bệnh viện Nhi Trung ương. Thời gian nghiên cứu từ tháng 9/2019 đến tháng 8/2020. Phương pháp nghiên cứu: nghiên cứu cắt ngang một loạt ca bệnh. Kết quả: Tỷ lệ mắc HCCH ở bệnh nhân TSTTBS thiếu 21-OH là $15,4 \%$ (8/52), tất cả bệnh nhân có tình trạng tăng vòng bụng và tăng triglycerid, $7 / 8(87,5 \%)$ bệnh nhân có tình trạng kháng insulin và thừa cân, béo phì, $50 \%$ bệnh nhân có rối loan glucose máu, chỉ hai bênh nhân tẳng huyết áp. $5 / 8(62,5 \%)$ bệnh nhân mắc hội chứng chuyển hóa có kiểm soát bệnh kém. Kết luận: Hội chứng chuyển hóa là một vấn đề mới cần quan tâm ở bệnh nhân tăng sản thượng thận bẩm sinh thiếu 21-a hydroxylase.

Tư khóa: Hội chứng chuyển hóa, tăng sản thượng thận bẩm sinh

\section{SUMMARY \\ METABOLIC SYNDROME IN PATIENTS WITH CONGENITAL ADRENAL HYPERPLASIA DUE TO 21-a HYDROXYLASE DEFICIENCY}

A metabolic syndrome (MetS) is a group of risk factors for cardiovascular risks and increased mortality in adults and children. Evidence shows that patients with congenital adrenal hyperplasia due to 21-a hydroxylase deficiency (CAH) have many factors leading to metabolic syndrome and an increased risk of cardiovascular risks. Objectives: to determine the incidence and characterize the metabolic syndrome in

${ }^{1}$ Bệnh viện Nhi Trung ương

${ }^{2}$ Trường Đai hoc Y Hà Nôi

Chịu trách nhiệm chính: Vũ Chí Dũng

Email: dungvu@nch.org.vn

Ngày nhân bài: 18.12 .2020

Ngày phản biên khoa hoc: 26.01.2021

Ngày duyệt bài: 2.2 .2021

\section{Vũ Chí Dũng1, Hoàng Xuân Đạii ${ }^{2}$}

the population of congenital adrenal hyperplasia with 21- a hydroxylase deficiency. Subjects: 52 patients with $\mathrm{CAH}$ aged 10 years and older were diagnosed, managed and followed up at Viet Nam National Children's Hospital. From July 2019 to August 2020. Methods: A cross-sectional description. Results: The incidence of metabolic syndrome in patients with congenital adrenal hyperplasia due to 21-a hydroxylase deficiency was $15.4 \%(8 / 52)$, all patients with increased waist circumference and hypertriglyceridemia, $7 / 8(87.5 \%)$ patients with insulin resistance and overweight, obesity, half of the patients have impaired blood glucose, only two patients with hypertension. $5 / 8(62.5 \%)$ of patients with metabolic syndrome have poor control. Conclusions: Metabolic syndrome is a new problem in patients with congenital adrenal hyperplasia due to 21-a hydroxylase deficiency.

Keywords: metabolic syndrome, congenital adrenal hyperplasia

\section{I. ĐĂT VẤN ĐỀ}

Tăng sản thượng thận bẩm sinh (TSTTBS) là một nhóm các bệnh di truyền lặn nhiễm sắc thể thường, đặc trưng bởi thiếu hụt tổng hợp cortisol vỏ thượng thận do khiếm khuyết một trong các enzyme tham gia quá trình tổng hợp steroid thượng thận. TSTTBS thiếu 21-a hydroxylase (21-OH) do đột biến gen CYP21A2 là phổ biến nhất, chiếm tỳ̉ lệ 90-95\% [1]. Thiếu 21-OH dẫn đến giảm sản xuất cortisol, aldosterone và gia tăng các tiền chất steroid trước vị trí enzyme bi thiếu. Giảm cortisol kích thích thùy trước tuyến yên tăng bài tiết hormone hướng vỏ thượng thân (adrenocorticotropic hormome -ACTH) dẫn đến tăng kích thước tuyến thượng thận và tăng sản xuất androgen. Hậu quả của thiếu hụt $21-\mathrm{OH}$ là cơn suy thượng thận, bất thường sinh dục gây nam hoá ở trẻ gái, vô kinh, vô sinh ở nữ, dậy thì sớm giả ở nam. Sự ra đời của liệu pháp hormone thay thế (hydrocortisone và fludrocortisone) đã giúp cải thiện tỷ lệ tử vong và tình trạng bệnh. Tuy nhiên, bổ sung hormone phù hợp nhịp sinh học và nhu cầu của từng cá thế vẫn là một thách thức lớn. Sự kết hợp của thừa hoặc thiếu cortisol, thừa hoặc thiếu androgen, và suy giảm 